\title{
Interview
}

\section{Early work on the function of CD95, an interview with Shige Nagata}

\author{
S Nagata ${ }^{*, 1,2}$ \\ 1 Department of Integrated Biology, Graduate School of Frontier Bioscience, Osaka University, 2-2 Yamada-oka, Suita, Osaka 565-0871, Japan \\ 2 Department of Genetics, Graduate School of Medicine, Osaka University, 2-2 Yamada-oka, Suita, Osaka 565-0871, Japan \\ * Corresponding author: S Nagata, Department of Integrated Biology, Graduate School of Frontier Bioscience and Department of Genetics, Graduate School of \\ Medicine, Osaka University, 2-2 Yamada-oka, Suita, Osaka 565-0871, Japan. Tel: + 81-6-6879-3310; Fax: + 81-6-6879-3319; \\ E-mail: nagata@genetic.med.osaka-u.ac.jp
}

Cell Death and Differentiation (2004) 11, S23-S27. doi:10.1038/sj.cdd.4401453

Published online 14 May 2004

This interview is part of a series of articles to mark the 10th anniversary of Cell Death and Differentiation.

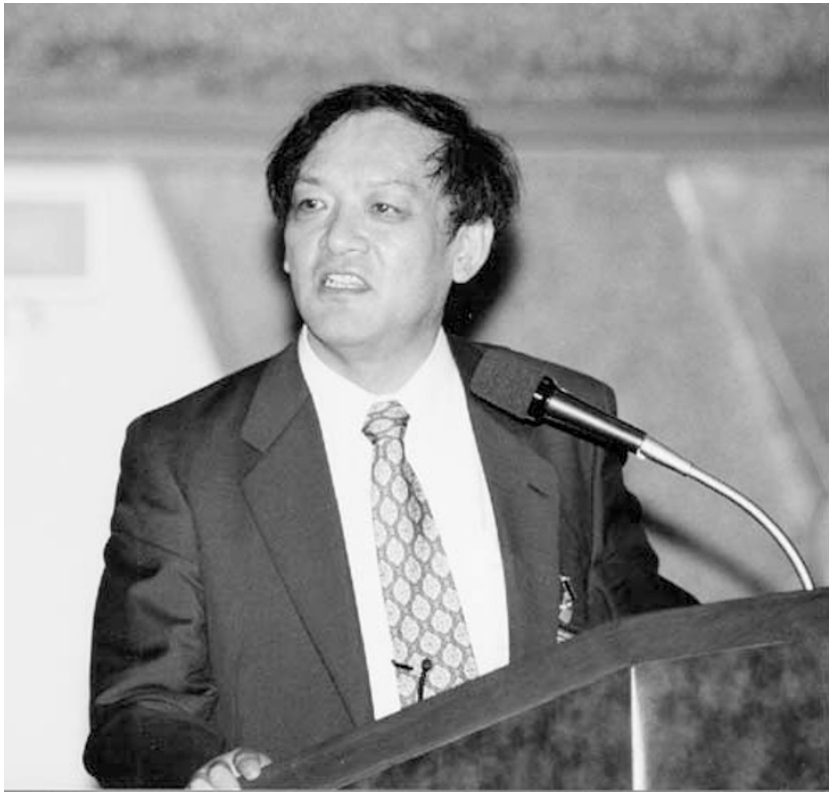

Dr. Nagata is a Professor in the Graduate School of Frontier Bioscience, Osaka University. His group is working on molecular mechanism and physiological roles of apoptosis, and on the signal transduction triggered by cytokines. Dr. Nagata serves as an editorial board member in various journals that include Cell Death Differentiation, Immunity, and Cancer Cell. He has received various awards such as Emil von Boehring Prize, Robert Koch Award, Prix Lacassagne, Mellon Prize, Japan Academy, and Imperial Prize. In 2001, he was recognized as a Person of Cultural Merit by the Japanese Government.

CD95, also called Fas or APO-1, was the first death receptor of the apoptotic mechanism to be molecularly characterized in any organism. CD95 ligand (Fas ligand) is expressed in activated $\mathrm{T}$ cells and NK cells and mediates immune responses. The existence of a large family of death receptors has now been recognized. Some death receptors such as CD95 are expressed in various human cancer cells, suggest- ing that death receptors have relevance to human diseases such as cancer. Here, Cell Death and Differentiation asks professor Shigekazu Nagata about the early work on CD95.

\section{CDD: What did you work on during your postdoc in Switzerland?}

As a Ph.D. student (1972-1977) at the University of Tokyo, I worked on an enzyme called 'Polypeptide chain elongation factor 1 (EF-1)'. I purified this enzyme from pig liver and characterized it biochemically. ${ }^{1,2}$ During this period, recombinant DNA technology was developed in the USA and Europe..$^{3,4}$ I thought that this new technique was revolutionary and would change the way Bioscience was conducted. Since nobody in Japan was working with the recombinant DNA technology at that time, I decided to go to Dr. Charles Weissmann's laboratory in Switzerland in 1977. I first learned recombinant DNA technology using $\mathrm{Q} \beta$ phage, and then I became engaged in cloning of the cDNA for human leukocyte interferon (IFN $\alpha$ ). After a year of hard work, we found an Escherichia coli clone producing human IFN $\alpha$ on December 24, 1979. , $^{5}$

\section{CDD: How was CD95 first identified?}

In 1982, I returned to Tokyo (Institute of Medical Science, University of Tokyo). One of my interests was the signal transduction pathway that was activated by IFN. I collaborated with Dr. Shin Yonehara in The Tokyo Metropolitan Institute of Medical Science to characterize the human IFN receptor. ${ }^{7}$ To obtain a monoclonal antibody (mAb) against the human IFN receptor, Dr. Yonehara immunized mice with the human fibroblast cell line FS-7, and then screened the library for the anti-human IFN receptor; in doing this, he accidentally found an $\mathrm{mAb}$ that had a cytopathic activity against human FL cells. ${ }^{8}$ 
The antigen recognized by the antibody was designated as the Fas antigen (FS-7-associated surface antigen), which was later redesignated 'CD95'.

\section{CDD: How did you clone CD95?}

In 1987, I moved to a new Institute in Osaka (Osaka Bioscience Institute) as the head of the Department of Molecular Biology. Dr. Yonehara asked me to collaborate on a project to clone the cDNA for human Fas. The $M_{\mathrm{r}}$ of human Fas was reported to be $200 \mathrm{kDa}^{8}{ }^{8}$ so I thought that cloning of the cDNA for such a huge molecule would be an extremely difficult project. Yet, I asked Dr. Nobuhara (a chief manager of Mochida Pharmaceutical Co.) to help me on this project. He agreed and Mr. Mizushima came from the company to my laboratory in 1988. Mr. Mizushima constructed a cDNA library using a lambda-based expression vector, and screened the library with the anti-Fas antibody (IgM) that was sent to us by Dr. Yonehara. This approach was unsuccessful. Next, Mr. Mizushima constructed a powerful mammalian expression vector $^{9}$ using the human EF-1 $\alpha$ promoter, and tried to clone the Fas cDNA by expression cloning in mammalian cells. In 1990, Mr. Mizushima returned to the company and Dr. Naoto Itoh, who had learned the panning-based expression cloning while at the DNAX Institute (USA), ${ }^{10}$ joined us, took on this project, and rather quickly (within a year) identified the Fas cDNA. ${ }^{11}$ To our surprise, human Fas was composed of 319 amino acids with a predicted $M_{\mathrm{r}}$ of $36 \mathrm{kDa}$, not $200 \mathrm{kDa}$.

\section{CDD: Why did you move to the study of apoptosis?}

To explain the cytotoxic activity of the anti-Fas antibody, we originally thought of two possibilities. The first was that Fas could be a receptor for a growth or survival factor, or a surface protein involved in the transport of nutrients such as amino acids or sugar. In this case, the anti-Fas antibody would work as an antagonist by blocking the action of the growth factors or by preventing the transport of nutrients. The second possibility was that Fas could be the receptor for a death factor, and the anti-Fas antibody might work as an agonist mimicking the death factor. To distinguish between these possibilities, we established mouse cell transformants that expressed human Fas. Treating the transformed cells with an anti-human Fas antibody that does not react with mouse Fas killed the transformants. We thus concluded that Fas is a receptor that mediates the transduction of a death signal into cells.

Kerr et a/ ${ }^{12}$ divided cell death into two categories: apoptosis and necrosis. When mouse cells expressing human Fas were treated with the anti-human Fas antibody, their DNA was degraded into nucleosomal units, one of the hallmarks of apoptosis. ${ }^{13}$ We concluded that Fas kills the cells by activating the apoptotic program, and submitted a manuscript to Cell. ${ }^{11}$ All three reviewers recommended publication with enthusiasm, and one of them advised us to carry out an analysis of the dying cells by electron microscopy. We did this, and the analysis showed the typical apoptotic condensation and fragmentation of cells, which convinced us that Fas indeed mediates apoptosis.

\section{CDD: How did you learn about the identity of Fas and APO-1?}

In 1989, Dr. Peter Krammer in Heidelberg established an mAb (anti-APO-1) that induced apoptotic cell death in lymphoblast cell lines. ${ }^{14}$ The $M_{r}$ of the molecule recognized by the APO-1 antibody was reported to be $52 \mathrm{kDa}$. This $M_{\mathrm{r}}$ was quite different from that initially predicted for the Fas antigen $(200 \mathrm{kDa}){ }^{8}$ However, the cloned human Fas cDNA encoded a glycoprotein of $52 \mathrm{kDa}$. Fas, like APO-1, was found to be expressed in various transformed hemopoietic cells, including lymphoma, myeloid leukemia, and HTLV-1-transformed cells. The identity of Fas with APO-1 was then showed by cloning of the APO-1 cDNA. ${ }^{15}$

\section{CDD: How did you clone the CD95 ligand?}

The structure of CD95 indicated that it belongs to the TNF receptor family, suggesting that CD95 should have a natural ligand. To search for the CD95 ligand, Dr. Takashi Suda, who came back to Japan from the DNAX Institute to join our group in April 1992, constructed a hybrid protein consisting of the extracellular region of CD95 and the Fc region of human IgG. By FACS analysis with the chimeric protein, Dr. Suda together with Mr. Tomoyuki Takahashi, who came to my laboratory from Mochida Pharmaceutical Co. in September 1992, screened more than 100 cell lines for the presence of the CD95 ligand on the cell surface. We also used Western blotting to screen the supernatants of various cell lines and human serum and urine samples for the soluble CD95 ligand. All our efforts were in vain.

Then, on the evening of December 15, 1992, I received a surprising Fax from Dr. Pierre Golstein (INSERM, Marseille) whom I had never met. In his Fax, Pierre said that he had found a CTL cell line (d10S) that kills target cells via the Fas-Fas ligand pathway, ${ }^{16}$ and he asked me whether I was interested in obtaining the cell line from him. I immediately sent back a Fax to Pierre, and the cell line arrived at Osaka within a week. Dr. Suda quickly confirmed the presence of the CD95 ligand on the cell surface of d10S. Since its expression level was not very high, Dr. Suda performed repeated FACS sorting of the population of d10S to isolate a subset that abundantly expressed the CD95 ligand. From this subpopulation, Dr. Suda prepared a cDNA library in a mammalian expression vector, and cloned the CD95 ligand by the panning method using CD95-Fc. After defining the CD95 ligand as an apoptosis-inducing death factor, we submitted a manuscript to Cell on October 4, 1993. On October 12, I went to New York to attend the Meeting on Apoptosis at Banbury Center at Cold Spring Harbor. At this meeting, I met Dr. Pierre Golstein for the first time! On October 14, a Fax from Cell was forwarded from Osaka to me at Cold Spring Harbor. The Fax contained very enthusiastic comments from all three referees of our manuscript. I shook hands with Pierre. The paper was published on December 17, $1993,{ }^{17}$ just 1 year to the day from when I received Pierre's first Fax. 


\section{CDD: If CD95 only helps human immune cell interactions, why did you look for CD95 in mouse models?}

The characterization of the human CD95 system led us to propose the existence of a death factor and its receptor. I was educated as a biochemist, and learned from Arthur Kornberg that 'Most people would suspect that the differences between a microscopic bacteria and an elephant far outweigh their similarities, but in fact, the similarities of genetic inheritance and biochemical metabolism are far greater than the obvious differences in their forms and organization'. ${ }^{18}$ It is my conviction that if it is true for humans, it must be true in mice and vice versa. In any case, I am not an M.D., so I had to work with a mouse model system.

\section{CDD: Were there any clinical implications of this work?}

CD95 is expressed in transformed lymphoblastoid cells. Since these cells are sensitive to the apoptosis triggered by the antiAPO-1, or anti-Fas, antibody, it was first hoped that these antiCD95 antibodies could be used for cancer therapy. In fact, injection of the anti-human APO1 antibody into nude mice carrying human tumors caused tumor regression. ${ }^{14}$

After identifying the mouse CD95 cDNA, we wanted to have mAbs against mouse CD95 to characterize CD95's expression in mouse cells and tissues. Dr. Jun Ogasawara, who came to my laboratory in January 1992 as a guest researcher from Osaka City Institute of Public Health and Environmental Science, established a mouse lymphoma line transformed with mouse CD95. He used the CD95-overexpressing cells to immunize Armenian hamsters, and a hybridoma (Jo2) that produced an anti-CD95 antibody was identified. To prepare the antibody in large quantities, he injected the hybridoma into the peritoneal cavity of nude mice. However, the next morning he found all the mice dead. Dr. Ogasawara repeated the injection of the Jo2 hybridoma, but once again found all the mice dead. I therefore advised him to grow the hybridoma in vitro. The purified $\mathrm{mAb}$ was then injected into the peritoneal cavity. Within a few hours, all the mice that received the antibody were killed. Dr. Ogasawara and I were stunned to see the dead mice on the bench, and could not figure out what was going on. Dr. Ogasawara then opened the belly of one of the mice. Dr. Naoki Shirafuji, the only M.D. in my laboratory that time, passed us, looked at the dead mice, and immediately pointed out that the liver was strange. He advised us to examine the biochemical parameters such as the levels of GOT (glutamate-oxalate transaminase) and GPT (glutamate-pyruvate transaminase) in the mouse serum, and to analyze the liver histochemically. Dr. Ogasawara carried out these analyses, and we concluded that the agonistic antibody (Jo2) against CD95 activated the apoptotic pathway in the hepatocytes that constitutively express CD95, and killed the mice by inducing fulminant hepatitis. ${ }^{19}$ Our conclusion was that if the CD95 ligand or the agonistic anti-CD95 antibody was systemically injected into human patients, it would kill the patients before it made the tumors regress.

\section{CDD: So how did you happen on the Ipr mice?}

When we clone a gene, we routinely determine its chromosomal location, hoping that we may find a linkage with a disease. In March 1991, when we cloned the mouse CD95 cDNA, we sent it to Dr. Nancy Jenkins ( $\mathrm{NCl}$, Frederick), asking her to assign its localization in mouse chromosomes. After 2 months, Nancy reported to us that the CD95 gene was on mouse chromosome 19 at a locus near which a gene for an autosomal recessive mutation called Ipr (lymphoproliferation) had recently been mapped. ${ }^{20}$ Mice carrying homozygous mutations in Ipr develop splenomegaly and lymphadenopathy. ${ }^{21}$ The genetically mapped position of the CD95 gene was $5 \mathrm{cM}$ (about $5000 \mathrm{~kb}$ ) away from the Ipr locus, but we could not abandon our naïve idea that if CD95, a receptor mediating apoptotic cell death, was mutated, cells that should die could not die, and might proliferate, causing lymphadenopathy. Our observation of the abundant expression of CD95 in the mouse thymus and spleen ${ }^{22}$ supported this idea.

\section{CDD: What did you do with the Ipr and gld (generalized lymphoproliferative disease) mice?}

I thought that if we could get Ipr mice, it would be easy to examine whether Ipr was a mutation of CD95. The Ipr mice were not commercially available at that time in Japan. I searched Medline for Japanese scientists working with Ipr mice, and found a group in Tokyo that had the mice. In July 1991, I went to Tokyo and obtained several mice from Dr. Katagiri at the Institute of Medical Science, University of Tokyo. I returned with the mice to Osaka via Super Express (the charming young lady who had the next seat in the train had an unpleasant 3-h trip due to the bad smell of the mice). In Osaka, Ms. Rie Watanabe-Fukunaga prepared RNA from the Iprmice, and found that the CD95 mRNA was not expressed in their thymus or spleen! She then prepared DNA from the mice and found a rearrangement in the CD95 gene. There is also a different allele for $I p r$ called $I p r^{\varepsilon g}$. I once again went to Tokyo and obtained $l p r^{c g}$ mice from Dr. Matsumura. The mice were transported to Osaka with me this time by airplane (I explained to the airline that they were my pets). Rie found a nonfunctional point mutation in the middle of the cytoplasmic region of CD95 of these mice. I prepared a manuscript during the X'mas-New Year Vacation, and it was published in March 1992 as a Nature Article. ${ }^{23}$

Mice carrying the gld mutation have a clinical syndrome that is indistinguishable from that of $l p r$ mice. Like $l p r, g l d$ is an autosomal recessive mutation, but this mutation was mapped to mouse chromosome $1 .{ }^{24}$ Through bone marrow transplantation experiments, a group at Jackson Laboratory demonstrated that the $I p r$ and gld mutations are expressed in different cell compartments and affect an interacting pair of molecules. ${ }^{25}$ Accordingly, the CD95 ligand gene was localized to the gld locus of mouse chromosome 1, and a nonfunctional point mutation was found in the CD95 ligand gene of gld mice. ${ }^{26}$ 


\section{CDD: What other work was being done at the time on CD95?}

I was interested in the cytokine system. From 1982-to 1987 in Tokyo, I collaborated with Dr. Shigetada Asano, a clinical hematologist, to clone the cDNA for granulocyte colonystimulating factor (G-CSF), which we succeeded in doing in 1986. ${ }^{27}$ We continued to work on G-CSF in Osaka, identified the cDNA for the G-CSF receptor, ${ }^{28}$ and studied the signal transduction pathway mediated by the receptor. ${ }^{29}$

\section{CDD: Why did you move from the Osaka Bioscience Institute to Osaka University? What is different about your new position?}

Osaka Bioscience Institute was established in 1987 as an institute for Basic Science (Director, Dr. Osamu Hayaishi). I joined this Institute from the beginning as a charter member. The Institute was not very big (four departments with 70 scientists and technicians), well equipped, and an easy place to work. I had no teaching duties, and there were few faculty meetings. The Institute was mostly supported by the City of Osaka. The Institute provided me with several postdoctoral fellows, technicians, and basic grants. I thus did not have to spend time writing grant applications. I could work on whatever projects I wished. This Institute, which was established solely because of the leadership of Dr. Hayaishi, is very different from any of the Japanese Universities. When the Institute was funded, Dr. Hayaishi and the charter members thought that it would be important to change the head of Department within 10 years to keep the Institute young and active. Therefore, in 1996, I moved to Osaka University Medical School. Yes, there are big differences between the Osaka Bioscience Institute and Osaka University. But, I, at this age, can enjoy teaching in the Medical School, and working with graduate students in the laboratory is fun. In the Medical School, I can collaborate with many different groups, including clinicians. I still do not like faculty meetings. At first, I simply did not attend the meetings, but I recently (unfortunately) have had to chair the committee. I like to discuss Science, but hate discussing Science policy.

\section{CDD: How was it that you started to work on the CAD/ICAD story?}

DNA fragmentation is a hallmark of apoptosis. As a biochemist working in this field, the identification of the factor responsible for the DNA fragmentation was a kind of dream. Several enzymes and factors such as DNase I, DNase II, and cyclophilin had been proposed as candidates for causing the DNA fragmentation. However, I was uneasy about the likelihood of these factors being responsible.

At the end of 1992, Dr. Hubert Hug, a former student of Dr. Charles Weissmann, came to my laboratory as a postdoctoral fellow. He, together with Masato Enari, a Ph.D. student from Yokohama City University, started dissecting the apoptotic signal induced by CD95. At first they investigated the effect of various inhibitors (kinase and phosphatase inhibitors), antioxidants, CAMP, etc., on CD95-mediated apoptosis, but none of these reagents affected the apoptosis. Meanwhile, in January 1994, I was invited to give a talk at a Mini Symposium at UCSF. At this Symposium, Dr. Horvitz presented evidence that CED3 is a homologue of ICE (interleukin $1 \beta$-converting enzyme, caspase 1). ${ }^{30}$ To examine the possible involvement of ICE in the CD95-mediated apoptosis, Enari established Rat1 cell transformants expressing crmA (a virus-coded ICE inhibitor) and showed that the transformants were resistant to the CD95-mediated apoptosis. ${ }^{31}$ We subsequently detected caspase activity in the cytoplasm of the CD95-activated cells. $^{32}$

CD95 is a cell-surface protein. The signal(s) generated by CD95 must begin in the cytoplasm. We thought that, like caspases, the factor that causes the DNA fragmentation might accumulate in the cytoplasm. Enari examined this possibility, and found that extracts from the dying cells, but not from living ones, induced the morphological changes of apoptosis, including DNA fragmentation in isolated nuclei. ${ }^{33}$ If the cells were pretreated with caspase inhibitors, CD95 did not induce the DNA fragmentation. On the other hand, the DNA fragmentation activity in the extracts from the dying cells was not inhibited by caspase inhibitors, indicating that the factor was downstream of caspase in the signal pathway. In fact, when cell extracts from healthy cells were treated with caspase, the extracts now caused the DNA fragmentation in nuclei. Since the factor digested naked DNA, we concluded that there was a DNase that could be activated by caspase, and this factor was designated as CAD (caspase-activated DNase).

\section{CDD: What happened next?}

First, we tried to purify CAD (the activated DNase) from apoptotic cells. However, the factor was very labile and scanty. We then changed our strategy, and tried to purify the precursor of CAD. That is, extracts from healthy cells were fractionated and assayed for the DNase activity in the presence of caspase-3. This approach was promising, but we had a problem with the starting materials: we did not have a large-scale culture system for mammalian cells. We tried using pig liver and calf thymus, but with no success (the expression level of CAD in these tissues was low). I then remembered that the Ipr mice have big lymph nodes and spleens. I found that the Japanese Animal Agency kills many aged and retired Ipr mice every week. We got these mice for free (!), and Enari started to purify CAD from their lymph nodes, which contained homogeneous populations of lymphocytes expressing CAD at high levels.

In 1996, I moved to Osaka University Medical School with my research group, and a new graduate student, Hideki Sakahira, joined us. His project was to elucidate why HTLV-1transformed cells were resistant to CD95-induced apoptosis. He prepared extracts from the HTLV-1-transformed cells, and found that the extracts could inhibit CAD. This inhibiting factor was designated ICAD (inhibitor of CAD), and was found to be present not only in HTLV-1-transformed cells but also in normal, nontransformed cells. Unlike activated CAD, ICAD 
was very stable, and was resistant to heat and SDS. Thanks to this property, ICAD was quickly purified by Sakahira. Recombinant ICAD efficiently inhibited CAD's DNase activity, and was used to pull out activated CAD. Two manuscripts dealing with CAD and ICAD were submitted to Nature on November 19, 1997. We received a reply from Nature on November 26 saying that if the manuscripts were revised within 1 week, they would be published on January 1 , $1998 !^{34,35}$

\section{CDD: So you had the same assistants for several years? Was this a united team effort?}

I had many research associates, postdoctoral fellows, and graduate students. Some of them stayed in my laboratory for several years. Dr. Naoto Itoh (1990-1993) cloned CD95, Dr. Jun Ogasawara (1992-1993) established the Jo2 hybridoma, Dr. Takashi Suda (1992-1998) and Tomoyuki Takahashi (1992-1995) identified the CD95 ligand and characterized the gld mutation, and Dr. Masato Enari (1993-1998) and Dr. Hideki Sakahira (1996-2000) identified the CAD and ICAD system. Many other young and talented scientists and students worked in my laboratory. I enjoyed my collaboration with them. Without their devotion to science, and their dedication to teamwork, I am sure that we could not have done anything.

\section{CDD: What music do you like to listen to and what do you most like to eat?}

I like to listen to Japanese popular songs (ENKA). I like Italian food (Spaghetti and sea foods). However, I usually take the Japanese menu in the return flight from Europe or USA.

\section{CDD: What kinds of meetings do you like best, and why?}

I prefer small meetings, so that we can talk intimately with each other. I prefer meetings in big cities such as New York and Paris. I have to travel a long distance from Osaka. For example, there is a direct flight from Tokyo to New York. The trip from Osaka to New York via Tokyo is about $16 \mathrm{~h}$. It takes more than $24 \mathrm{~h}$ to get to Keystone, and I am too tired when I arrive at the conference to enjoy it fully.

\section{Acknowledgements}

Professor Shigekazu Nagata is grateful to the funding bodies that supported this work, in particular, the City of Osaka, Ministry of Education, Science, Sports and Culture in Japan, and Japan Science Technology Co. $\mathrm{He}$ is indebted to many colleagues who contributed help, reagents, ideas and discussions, but Shige Nagata would especially like to acknowledge the help, insight, and friendship of Dr. Pierre Golstein.

1. Iwasaki K et al. (1974) J. Biol. Chem. 249: 5008-5010

2. Nagata S, Iwasaki K and Kaziro $Y$ (1977) J. Biochem. (Tokyo) 82: 1633-1646

3. Efstratiadis A et al. (1976) Cell 7: 279-288

4. Maniatis T et al. (1976) Cell 8: 163-182

5. Nagata $S$ et al. (1980) Nature 284: 316-320

6. Weissmann C (1981) Gresser I (eds) (London: Academic Press) pp. 101-134

7. Yonehara S et al. (1983) J. Biol. Chem. 258: 9046-9049

8. Yonehara S, Ishii A and Yonehara M (1989) J. Exp. Med. 169: 1747-1756

9. Mizushima S and Nagata S (1990) Nucleic Acids Res. 18: 5322

10. Itoh $\mathrm{N}$ et al. (1990) Science 247: 324-327

11. Itoh $\mathrm{N}$ et al. (1991) Cell 66: 233-243

12. Kerr JF, Wyllie AH and Currie AR (1972) Br. J. Cancer 26: 239-257

13. Wyllie AH (1980) Nature 284: 555-556

14. Trauth BC et al. (1989) Science 245: 301-305

15. Oehm A et al. (1992) J. Biol. Chem. 267: 10709-10715

16. Rouvier E, Luciani M-F and Golstein P (1993) J. Exp. Med. 177: 195-200

17. Suda T et al. (1993) Cell 75: 1169-1178

18. Kornberg A (1989) For the Love of Enzymes: The Odyssey of a Biochemist. Cambridge, MA: Harvard University Press

19. Ogasawara J et al. (1993) Nature 364: 806-809

20. Watanabe T et al. (1991) Biochem. Genet. 29: 325-336

21. Cohen PL and Eisenberg RA (1992) Immunol. Today 13: 427-428

22. Watanabe-Fukunaga $R$ et al. (1992) J. Immunol. 148: 1274-1279

23. Watanabe-Fukunaga $R$ et al. (1992) Nature 356: 314-317

24. Seldin MF et al. (1988) J. Exp. Med. 167: 688-693

25. Allen RD et al. (1990) J. Exp. Med. 172: 1367-1375

26. Takahashi T et al. (1994) Cell 76: 969-976

27. Nagata $S$ et al. (1986) Nature 319: $415-418$

28. Fukunaga $R$ et al. (1990) Cell 61: 341-350

29. Fukunaga $R$, Ishizaka-lkeda $E$ and Nagata $S$ (1993) Cell 74: 1079-1087

30. Yuan J et al. (1993) Cell 75: 641-652

31. Enari M, Hug $\mathrm{H}$ and Nagata S (1995) Nature 375: 78-81

32. Enari $\mathrm{M}$ et al. (1996) Nature 380: 723-726

33. Enari M, Hase A and Nagata S (1995) EMBO J. 14: 5201-5208

34. Sakahira H, Enari M and Nagata S (1998) Nature 391: 96-99

35. Enari M et al. (1998) Nature 391: 43-50 